\title{
PENGENDALIAN DAN PENGELOLAAN TIM LINTAS FUNGSIONAL DALAM ORGANISASI
}

\author{
Supardi \\ Akademi Akuntansi YKPN \\ e-mail: dee_pard@yahoo.com
}

\begin{abstract}
The complexity of modern business and the need for quick responses to changing conditions don't allow employees to go through channels anymore. But many companies have a hard time combining information, action and interpretation across old structural boundaris, like hierarchical organization. Often, the result is decisions so untimely as to be irrelevant, no matter how technically correct they are. In today's business environment, companies need the team concept to increase productivity and profitability, enhance quality, beat competition, or achieve the company objective du jour. Cross-functional teams (CFTs) have increased in use within a variety of organizations. While these teams claim to enhance organizational effectiveness, research has seen mixed results. This paper examines the challenges faced by CFTs and why these challenges facilitate the need for the development of a teams climate for trust.
\end{abstract}

Keyword: cross-functional team, hierarchical organization

\section{PENDAHULUAN}

Globalisasi ekonomi yang melanda seluruh dunia secara cepat membuka paradigma baru bagi manajemen di perusahaan-perusahaan seluruh dunia, di mana persaingan tidak lagi terjadi sesama pesaing domestik, tetapi juga telah datang pesaing-pesaing mancanegara yang memiliki produk dan jasa yang sarat dengan keunggulan teknologi, informasi, dan pengetahuan. Hal ini juga memaksa perusahaan di Indonesia untuk "berlomba" menghasilkan produk dan jasa yang memiliki standar mutu perdagangan global. Menurut Mulyadi \& Johny Setyawan (1999:14), globalisasi ekonomi telah menciptakan lingkungan bisnis yang menyebabkan perlunya peninjauan kembali prinsip-prinsip manajemen yang digunakan oleh perusahaan untuk mampu bertahan dan bertumbuh dalam persaingan tingkat dunia. Untuk itu, manajemen perusahaan perlu merubah paradigma manajemen mereka agar sikap dan tindakan dalam menjalankan bisnis menjadi efektif.

Saat lingkungan bisnis masih stabil, di mana produsen memegang kendali bisnis, perusahaan membangun sistem manajemen yang sesuai dengan keadaan pada masa tersebut, yaitu melakukan pembagian fungsi sesuai dengan keahliannya. Sistem manajemen seperti ini biasanya menggunakan struktur organisasi yang bersifat hirarkis atau pendekatan fungsional hirarkis. Struktur organisasi hirarkis menurut Bound, et.al (1994:307), organisasi dibagi ke dalam tugas-tugas yang lebih kecil, mendefinisikan tugas serta tanggung jawab tersebut menjadi lebih sempit, serta memecah sistem ke dalam fungsi-fungsi atau departemen sesuai dengan keahlian masing-masing. Departemen tersebut 
biasaya akan dipimpin oleh manajer yang bertanggung jawab atas setiap fungsi yang dibentuk. Untuk mengukur kinerja dalam organisasi hirarkis, dilakukan dengan membentuk pusat-pusat pertanggung jawaban, seperti pusat biaya, pusat pendapatan, pusat investasi dan pusat laba.

Mulyadi \& Johny Setyawan (1999:126) mengatakan bahwa pendekatan fungsional hirarkis memandang organisasi sebagai mesin dan menggunakan metodologi analitik, yaitu sesuatu dapat dipahami dengan memecahnya ke dalam bagian yang lebih kecil. Pendekatan ini juga menganut pandangan reduksionisme, yaitu bagian dari sesuatu dapat dipahami dengan sendirinya melalui pemisahan bagian tersebut sampai dengan unsur pokok dapat ditemukan. Pendekatan fungsional hirarkis dilandasi keyakinan bahwa kinerja organisasi akan dapat dioptimalkan jika fungsi individu dioptimalkan dan bahwa keseluruhan dikelola melalui pengelolaan bagiannya.

Di zaman kompetisi global seperti sekarang ini, di mana perkembangan teknologi dan informasi semakin maju dan terjadinya pergeseran-pergeseran paradigma bisnis, seperti pergeseran kendali bisnis dari produsen ke konsumen, mengakibatkan perusahaan dituntut untuk menghasilkan barang dan jasa dengan lebih cepat dan memiliki kualitas baik yang akhirnya tetap dapat memikat minat konsumen. Keadaan lingkungan bisnis yang telah berubah menyebabkan individualisme melemah dan digantikan kerja tim. Tim dengan spesialisasi sudah tidak sesuai lagi dan mulai digantikan dengan tim yang terdiri dari keahlian yang berbeda. Menurut Mulyadi dan Johny Setiawan (1994:89), garis organisasi yang kaku seperti organisasi hirakis, menjadi tidak efektif dan mulai digantikan dengan kerjasama yang berubah-ubah. Kekuasaan telah hilang pengaruhnya dan digantikan dengan pemberdayaan anggota organisasi. Perubahan ini, menuntut organisasi menggunakan pendekatan baru dalam membangun organisasi. Cross Functional Approach merupakan pendekatan baru untuk membangun Cross Functional Organization yang memungkinkan terbentuknya Cross Functional Team dan dapat memnuhi tuntutan lingkungan bisnis saat ini. Berdasarkan penjelasan tersebut, penulis mencoba untuk membahas tentang tim lintas fungsional, alasan dibutuhkan tim lintas fungsional ini dan rintangan yang harus dihadapi untuk dapat sukses membantu organisasi.

\section{PENTINGNYA MEMAHAMI TIM}

Pada lingkungan bisnis seperti sekarang, sebagian besar perusahaan mengatakan bahwa untuk bisa bertahan, salah satu kunci sukses adalah dengan terus menerus membangun value bagi konsumen. Konsumen saat ini bagaikan raja yang harus terus menerus perusahaan "layani”. Kalau bisa, saat konsumen baru berencana membeli, produk tersebut sudah ditawarkan oleh perusahaan. Untuk mewujudkan value bagi konsumen, perusahaan memerlukan individu-individu yang memiliki kreatifitas yang tinggi. Kreatifitas tersebut dapat diperoleh melalui hubungan antar individu melalui suatu bentuk kerja tim (teamwork). Menurut Peter Strozniak (2000), membangun tim dalam organisasi adalah penting, karena teknologi dan permintaan pasar memaksa organisasi untuk dapat membuat produk yang lebih cepat, lebih murah dan lebih baik. Dengan menyatukan brain power seluruh karyawan dan memberdayakan mereka untuk mengambil keputusan adalah salah satu cara terbaik yang dapat membantu organisasi beradaptasi dengan perubahan ini.

Menurut Hasan Mustafa (2001), tim dibangun dengan tujuan untuk membantu kelompok fungsional menjadi lebih efektif. Karena rasa individualisme dan persaingan antar pribadi realtif tajam dalam organisasi, maka tidak semua kelompok kerja dapat dikategorikan ke dalam suatu tim. Secara spesifik, untuk membangun sebuah tim, organisasi harus mampu memahami sumber daya manusianya dan mengembangkan keadaan seperti di bawah ini : 
1. Semangat : Muncul karena masing-masing anggota percaya bahwa mereka memiliki kemampuan untuk menyelesaikan tugas. Makin tinggi tingkat kepercayaan mereka atas kemampuannya, makin besar motivasi dalam menyelesaikan tugas dengan baik.

2. Saling percaya : Rasa saling percaya antar anggota merupakan syarat mutlak yang harus dimiliki oleh setiap anggota tim, agar tim mampu bekerja secara efektif.

3. Kedekatan : Kedekatan antar anggota merupakan perasaan yang mampu menyatukan anggota secara sukarela. Suatu kelompok yang kohesif adalah kelompok yang dimiliki oleh setiap anggotanya. Mereka mempunyai tingkat loyalitas yang tinggi terhadap kelompoknya. Umumnya kelompok yang kohesif akan lebih produktif.

4. Komunikasi : Agar tim bisa berfungsi dengan baik, semua anggota harus mempunyai kemampuan untuk mengembangkan hubungan antar pribadi secara baik, bicara secara terbuka satu sama lain, memecahkan konflik yang ada, dan secara bersama menghadapi masalah.

5. Produktivitas : Tim seyogyianya dapat menyelesaikan tugas yang tidak mungkin dilaksanakan perorangan. Melalui saling berbagi sumber daya, keterampilan, pengetahuan, kepemimpinan, maka tim berpotensi sangat efektif daripada perorangan.

Membangun tim yang bersemangat, memiliki kedekatan, saling percaya dan produktif dapat dilakukan dengan banyak cara. Apapun caranya, hal yang penting diingat adalah tim itu sendiri harus mengembangkan kemampuan mengidentifikasi persoalan kerja mereka dan sekaligus juga memecahkannya.

\section{TIM LINTAS FUNGSIONAL}

Pergeseran kendali bisnis dari tangan produsen ke konsumen dan semakin kompetitif lingkungan bisnis menyebabkan dibutuhkan organisasi yang responsif terhadap kebutuhan konsumen. Pada masa lalu, organisasi yang berkembang adalah organisasi dengan struktur dan fungsional hirarkis, di mana organisasi membagi aktivitas pembuatan produk dan penyediaan jasa ke dalam pekerjaan terspesialisasikan yang dilaksanakan oleh pekerja yang memiliki kompetensi terspesialisasikan pula. Para spesialis yang memiliki kompetensi yang sama biasanya dikelompokkan dalam satu unit tim yang disebut departemen atau fungsi. Untuk melaksanakan koordinasi, manajer pada tingkat yang lebih tinggi bertanggung jawab terhadap tim yang ada dibawahnya, baru kemudian menyampaikan kepada manajer yang berada di tingkatan paling atas. Akibatnya tim tidak bisa dengan cepat untuk merespon atau mengambil keputusan sesegera mungkin. Jika hal ini terus berlanjut dan tidak mendapatkan perhatian, maka akan mengganggu kelangsungan hidup organisasi.

Di lingkungan bisnis saat ini, di mana kualitas menjadi ukuran keberhasilan suatu perusahaan, organisasi mulai mengadopsi atau menerapkan bentuk kerja tim yang dapat saling sharing informasi, cepat di dalam merespon perubahan lingkungan bisnis, dan mampu mengerjakan pekerjaan yang komplek. Tim yang dibentuk tersebut disebut tim lintas fungsional. Menurut Glenn M. Parker (1994), Tim Lintas Fungsional adalah suatu tim yang terdiri atas beberapa orang dari bermacam-macam departemen, disiplin ilmu atau fungsi yang bergabung untuk berusaha mewujudkan tujuan organisasi. Sedangkan Polly Kettley (2000) mengatakan bahwa, “Cross Functional Teams bring together diverse talents and encourage thinking outside the box. They have enormous potential for increasing the knowledge base of organizations. They can be very coal face of organizational learning, as well as enhancing the skills and abilities of individuals. They deserve, but not always receive, solid organizational support, and recognition from senior management”. 
Berdasarkan definisi di atas, maka anggota tim lintas fungsional adalah personel yang memiliki keahlian tertentu dibidangnya dan dipilih berdasarkan spesialisasi yang dibutuhkan untuk mencapai tujuan sistem dan berasal dari fungsi utama, dari fungsi pendukung atau bahkan dari luar organisasi (Mulyadi dan Johny Setyawan, 1999:93). Keanggotaan tim lintas fungsional dapat bersifat permanen atau bersifat ad hoc tergantung dari kebutuhan organisasi dalam menghadapi masalah (gambar 1). Anggota tim lintas fungsional dapat seorang individu yang memiliki spesialisasi keahlian yang dibutuhkan untuk mewujudkan tujuan sistem atau seorang manajer yang memimpin satu fungsi.

Tim lintas fungsional dapat berjalan dengan baik, jika tim lintas fungsional dipimpin oleh seorang manajer yang seringkali disebut sebagai case manager. Case manager memegang kepemilikan sistem dan bertanggung jawab untuk mencapai tujuan sistem yaitu pemuasan kebutuhan konsumen, dan melakukan pengmbangan yang berkelanjutan terhadap sistem tersebut serta bertanggung jawab untuk membangkitkan komitmen seluruh anggota tim dalam mencurahkan kompetensi mereka masingmasing. Case manager merupakan titik kontak tunggal bagi konsumen, baik konsumen internal maupun eksternal.

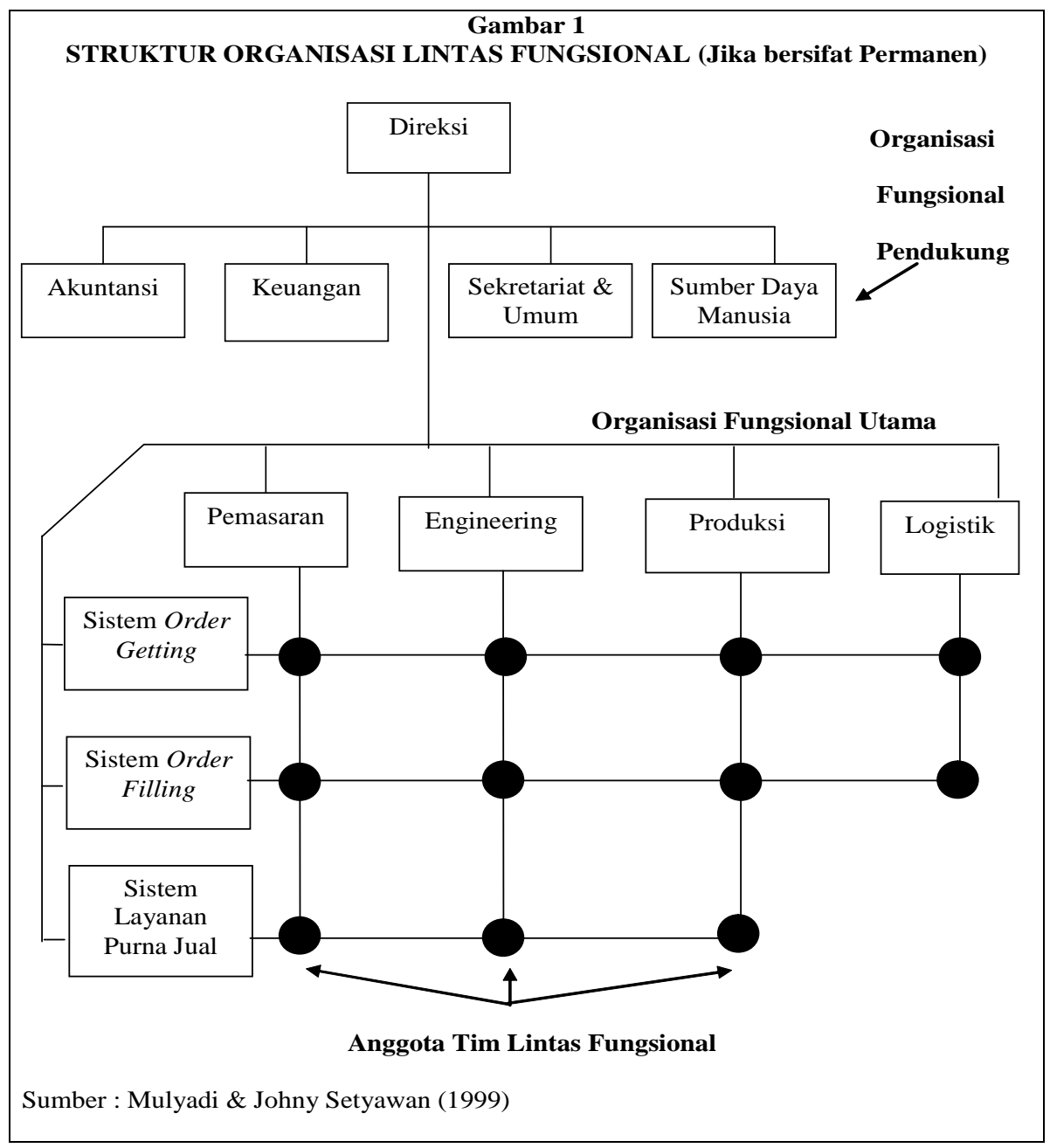




\section{MENGAPA TIM LINTAS FUNGSIONAL DIBUTUHKAN?}

Di zaman kompetisi global seperti sekarang ini, di mana perkembangan teknologi dan informasi semakin maju serta peranan teknologi informasi pada aktivitas manusia saat ini memang begitu besar. Teknologi informasi telah menjadi fasilitator utama bagi kegiatan-kegiatan bisnis yang memberikan andil besar terhadap perubahan-perubahan mendasar bagi struktur, operasi dan manajemen organisasi. Jenis pekerjaan dan tipe pekerja yang dominan di Jaman Teknologi Informasi adalah otonomi dan wewenang yang lebih besar dalam organisasi (Supriyati:2004).

Keadaan lingkungan bisnis yang telah berubah tersebut, menurut Glenn M. Parker (1994:3) membuat organisasi hirarkis telah kehilangan keandalannya dan telah digantikan dengan jejaring organisasi (Organization Network), organisasi yang berkemampuan untuk merespon dengan cepat perubahan lingkungan bisnis, khususnya dalam memenuhi kebutuhan konsumen. Menurut Supriyati (2004), untuk memenuhi kebutuhan konsumen yang kompleks, perusahaan membangun jejaring organisasi, yang di dalamnya setiap perusahaan menjadi anggota jejaring, sehingga mampu menghasilkan value terbaik bagi pelanggan, karena koordinasi tidak lagi dijalankan melalui “command and control mode" namun koordinasi dilaksanakan melalui komunikasi, persuasi dan kepercayaan (trust). Organisasi dibangun dengan kondisi Boundaryless organization, yaitu kondisi organisasi yang digunakan dalam teknologi informasi dengan batas-batas horisontal, vertikal, eksternal dan geografis yang sehat. Menipisnya batas horisontal mengakibatkan berkurangnya birokrasi sehingga organisasi menjadi lebih datar, dan karyawan menjadi lebih berdaya (empowered employees) dan menjadikan terwujudnya kerja sama lintas fungsional dalam memenuhi kebutuhan konsumen yang komplek. Menipisnya batas eksternal menjadikan perusahaan lebih berfokus ke penyediaan produk dan jasa yang menjadi kompetensi intinya (care competence).

Kekohesivan organisasi yang menggunakan tim lintas fungsional dan yang mempekerjakan karyawan yang berdaya, serta yang menggunakan jejaring organisasi dalam mewujudkan tujuan organisasi ditentukan dari seberapa jelas misi dan visi organisasi dirumuskan dan keberhasilan pengkomunikasian strategi tersebut kepada seluruh personel organisasi dan seluruh organisasi dalam jejaring. Pemberdayaan karyawan yang dilandasi oleh trust-based relationship antar manajer dan karyawan menjadikan Information sharing dapat meningkatkan tuntutan tentang otonomi dan wewenang di kalangan karyawan. Sedangkan persuasi menjadi pilihan untuk menggantikan komando, karena knowledge workers menjadi dominan dalam mewujudkan visi organisasi. dalam memacu komitmen karyawan untuk mengubah strategi menjadi tindakan nyata.

Mulyadi dan Johny Setyawan (1999:90) mengatakan bahwa ada dua alasan yang menyebabkan dibutuhkannya tim lintas fungsional yaitu, perlunya organisasi berorientasi ke sistem dan pandangan bahwa organisasi sebagai suatu sistem. Organisasi perlu berorientasi ke sistem karena seluruh personel organisasi diorientasikan ke sistem yang digunakan untuk menghasilkan value bagi konsumen. Sedangkan pandangan bahwa organisasi sebagai suatu sistem adalah menggambarkan organisasi sebagai suatu sistem terbuka yang berinteraksi dengan lingkungannya melalui arus kerja yang terdiri dari masukan, konversi, dan keluaran. Dalam organisasi itu sendiri, sebagai suatu sistem, organisasi merupakan kumpulan terpadu berbagai aktivitas personel, pengetahuan, kemampuan, motivasi, ekuipmen, mesin, metode, cara, proses, dan tugas yang ditujukan untuk menghasilkan value bagi konsumen.

Sedang menurut Glenn M. Parker (1998), alasan perlunya suatu organisasi membangun Cross Functonal Teams karena tim ini memiliki kelebihan yang unik dibandingkan dengan jenis tim-tim 
lainnya khususnya tim yang hanya terdiri dari individu dengan kemampuan seragam, yaitu :

1. Speed

Tim Lintas Fungsionals, mengerjakan sesuatu menjadi lebih cepat, terutama untuk pengembangan produk dan pelayanan terhadap konsumen.

2. Complexity

Tim Lintas Fungsionals memperbaiki kemampuan organisasi dalam mengatasi masalah yang komplek, karena tim ini terdiri dari orang-orang yang memiliki keterampilan, pengalaman, persepsi dan gaya yang berbeda.

3. Creativity

Kemajuan produk dan jasa baru berasal dari clash of idea bukan berasal dari hubungan antara karyawan yang memiliki pandangan sama.

4. Customer Focus

Tim ini memfokuskan seluruh usaha organisasi pada kepuasan konsumen baik konsumen internal maupun konsumen eksternal.

5. Organizational Learning

Anggota tim dapat mengambil keterampilan teknik dan profesional lebih mudah, mendapatkan pengetahuan penting tentang area organisasi lain, dan dapat mempelajari bagaimana bekerja dengan orang-orang yang memiliki gaya dan latar budaya yang berbeda.

6. Single Point of Contact

Tim menjadi lebih efektif dan efisien dengan mengidentifikasi satu tempat (biasanya disebut dengan case manager) untuk mendapatkan informasi dan keputusan yang terkait dengan proyek atau konsumen tanpa harus menunggu dari top manajer.

\section{RINTANGAN BAGI TIM LINTAS FUNGSIONAL}

Tim Lintas Fungsional dapat dibangun dengan mengurangi jumlah jenjang organisasi melalui program pemberdayaan karyawan yang lebih berorientasi kepada sistem. Pemberdayaan karyawan berarti memampukan dan memberi kesempatan kepada karyawan untuk merencanakan, mengimplementasikan rencana, dan mengendalikan implementasi rencana pekerjaan yang menjadi tanggung jawaabnya. Tim Lintas Fungsional didorong untuk memfokuskan orientasinya ke hubungan horizontal, bukan ke hubungan vertikal. Menurut Mulyadi dan Johny Setyawan (1999:137), Tim Lintas Fungsional akan memiliki kelemahan jika tetap terdapat informasi yang masih bersifat vertikal. Seperti pada gambar 1 , Tim Lintas Fungsional tetap berada pada kompleksitas organisasi hirarkis, di mana ada dua jenjang pimpinan yaitu direktur dan manajer. Isu tentang kekuasaan, wewenang, alokasi sumber daya, tujuan/ sasaran, dan hubungan pelaporan dapat menyulitkan usaha untuk melakukan pengembangan terhadap sistem.

Untuk dapat mewujudkan Tim Lintas Fungsional dalam organisasi bukan hanya sekedar menggabungkan potensi para personel dan menempatkan mereka dalam satu ruangan, tetapi harus berani menghadapi rintangan-rintangan yang ada agar tim lintas fungsional dapat sukses dan organisasi dapat merasakan keuntungannya. Glenn M. Parker (1998) menyebutkan rintangan-rintangan yang harus dihadapi oleh sebuah tim lintas fungsional, khususnya rintangan yang berasal dari dalam tim, adalah sebagai berikut:

1. The team leader must have both technical and process skills

Seorang pemimpin harus memiliki latar belakang teknis agar dapat memahami tujuan pokok 
pekerjaan tim dan mengenali potential constributions anggota tim yang terdiri dari orang-orang yang memiliki latar belakang yang bermacam-macam. Pemimpin harus pula mempunyai interpersonal skills untuk memudahkan hubungan dengan para anggota kelompok saat menghadapi pengalaman negatif dalam bekerja bersama-sama.

2. The team must be empowered to act decisively

Senior manajer harus memperjelas batasan kekuasaan yang tersedia bagi tim tersebut, menyediakan visi tim, overarching goal atau memberikan harapan umum sehingga pada gilirannya, mampu menterjemahkan ke dalam sasaran khusus dan suatu rencana terperinci.

3. Team objectives should be clear and specific

Tugas yang diemban oleh sebuah tim lintas fungsional harus jelas, spesifik dan harus mudah dipahami oleh setiap anggota tim. Sehingga kinerja tim dapat meningkat dan kesuksesan dapat diraih.

4. Cross functional teams need positive relationships with key stakeholders

Di dalam tim terdapat individu yang memiliki kedudukan atau jabatan yang memegang peranan kunci, seperti Senior management, Functional department head, Supplier dan Customer. Sehingga membangun hubungan dengan pihak lain di luar tim merupakan salah satu faktor yang dapat membuat tim menjadi sukses.

5. Team members want "credit" for their performance on the team Organisasi perlu memberikan "kredit khusus" atau reward terhadap kinerja anggota tim berdasarkan informasi yang diperoleh dari ketua tim.

6. Companies should consider project team reward and member recognition

Di dalam team-based organization, organisasi perlu merancang suatu program yang dapat memberikan reward kepada tim jika berhasil mencapai tujuan. Hal ini berguna untuk merangsang anggota tim dalam bekerja.

7. Cross functional teams should be small

Dalam membangun sebuah tim, jumlah anggota sangat mempengaruhi kinerja tim. Jika anggota tim terlalu banyak, menyebabkan komunikasi antar anggota tim menjadi terlalu sulit dan tidak efektif. Sehingga produktivitas tim akan cenderung menurun.

8. Positive interpersonal relationships are essential

Tim yang terdiri dari berbagai fungsi biasanya dapat mengakibatkan terjadinya konflik atau hubungan antar anggota menjadi rendah. Oleh sebab itu, organisasi harus mampu mengatasi dengan melakukan pelatihan dan konsultasi untuk mendesain tim yang cocok sesuai dengan karakter tim.

9. Management must support the team process

Agar tim dapat menjalani tugas dan tanggung jawabnya dengan baik, senior management harus terlibat dalam seluruh kegiatan tim, memberikan penilaian yang adil terhadap anggota tim, dan "memutus" status antara bawahan dan atasan.

10. Front-end training is a real plus

Setelah bekerja dalam tim dan bertanggung jawab atas tugas yang diembannya, tim perlu melakukan "penyegaran" dengan mengikuti pelatihan atau bertemu satu sama lain dengan suasana yang berbeda dan melibatkan individu di luar tim (sponsor team) untuk mendengarkan tujuan dan harapan organisasi terhadap proses tim.

Berdasarkan kesepuluh rintangan di atas, Tim Lintas Fungsional dapat mengalami masalah dan kesulitan jika tidak dapat mengatasinya. Oleh karena itu, organisasi perlu menyadari bahwa Tim 
Lintas Fungsional tidak berdiri sendiri tetapi harus didukung oleh seluruh komponen organisasi. Sehingga Tim Lintas Fungsional dapat berhasil dan memberikan manfaat bagi organisasi itu sendiri.

\section{KESIMPULAN}

Lingkungan bisnis yang telah mengalami perubahan pesat dan telah terjadi pergeseran kendali bisnis dari tangan produsen ke tangan konsumen, menyebabkan semakin besar tuntutan konsumen akan pelayanan yang semakin cepat. Jika perusahaan dapat memenuhi kebutuhan konsumen, maka perusahaan tersebut dapat dikatakan selalu memberikan nilai kepada konsumen dalam bentuk kepuasan konsumen. Agar perusahaan selalu dapat memberikan value bagi konsumen, maka hal tersebut memaksa perusahaan untuk selalu melakukan pengembangan secara berkelanjutan terhadap sistem yang digunakan. Salah satu pengembangan yang dilakukan oleh perusahaan adalah mengorganisasi sumber daya manusia, seperti membangun suatu tim yang lebih fokus terhadap pengembangan sistem bukan berfokus terhadap masing-masing fungsional. Tim seperti ini biasanya tim yang terdiri dari individu dan memiliki keahlian berbeda (Tim Lintas Fungsional).

Tim lintas fungsional dapat dikembangkan secara permanen dan menjadi bagian dalam struktur organisasi serta bertujuan untuk mewujudkan tujuan-tujuan jangka panjang. Selain itu, tim ini juga dapat bersifat ad hoc, yang bertujuan untuk mewujudkan tujuan jangka pendek dan tidak akan tampak dalam struktur organisasi perusahaan. Supaya dapat berjalan dengan baik dan sesuai dengan tujuan pembentukan tim, tim lintas fungsional dipimpin oleh seorang manajer yang disebut Case Manager. Case Manager merupakan titik kontak tunggal bagi konsumen di dalam memperoleh informasi.

Perubahan cara pandang organisasi terhadap perubahan tim, dari tim yang terdiri keahlian seragam dan informasi cenderung vertikal menjadi suatu tim yang multidisiplin ilmu/keahlian dan informasi lebih horizontal ini disebabkan karena tim ini dapat merespon perubahan-perubahan lingkungan bisnis dengan sangat cepat. Selain itu tim lintas fungsional memiliki keunggulan dalam hal mampu menyelesaikan pekerjaan dengan cepat, mampu menyelesaikan masalah yang kompleks, selalu berfokus terhadap kepuasan konsumen, meningkatkan kreatifitas anggota dan organisasi, dan menjadikan organisasi selalu belajar.

\section{DAFTAR PUSTAKA}

Bounds, Greg et al (1994). Beyond Total Quality Management: Toward the Emerging Paradigm. New York: McGraw-Hill International, Inc.

Mulyadi dan Johny Setyawan (1999). Sistem Perencanaan \& Pengendalian Manajemen: Sistem Pelipatganda Kinerja Perusahaan. Edisi ke 1. Aditya Media. Yogyakarta.

Parker, Glenn M. (1994). Cross Functional Teams: Working with Allies, Enemies, and Other Strangers. Jossey-Bass Publishers. San Fransisco.

Parker, Glenn M. (1998) Teaming with Strangers. Society of Insurance Trainers and Educators (SITE). 
Parker, Glenn M. (1994). “Rewarding Cross-Functional Teamwork”. R\&D Innovator. Vol. 3 No. 12.

Parker, Glenn M (1994). “Appraising Individuals in Cross Functional Teams”. R\&D Innovator. Vol. 3 No. 6.

Rajeth Sethi, Daniel C. Smith, and C. Whan Park (2002). “How to Kill a Team’s Creativity”. Harvard Business Review. August: 16-17.

Schmidt, Jeffrey B, Mitzi M. Montoya-Weiss, and Anne P. Massey (2001). "New Product Development Decision-Making Effectiveness: Comparing Individuals, Face-To-Face Teams, and Virtual Teams”. Decision Sciences. Vol. 32 No. 4.

Strozniak, Peter (2000). “Teams at Work”. Industry Week Magazine. September 18.

Sudrajat. “Penerapan Balance Score Card dan Manajemen SDM”. Seminar MSDM. Universitas Mercu Buana.

Supriyati. “Peranan Teknologi Informasi Dalam Audit Sistem Informasi Komputerisasi Akuntansi”. www. Jurnal.Unikom.ac.id/ed 9/04

Susanta (2005). “Turbo Marketing”. Jurnal Administrasi Bisnis. 